\title{
乾燥時の収縮挙動に及ぼす吒解状態の影響
}

\author{
山陽国策パルプ株 木 島 常 明，山 川

\section{Effect of Beating Condition on Shrinkage during Drying}

功

\author{
Tsuneaki Kijima and Isao Yamakawa \\ Tokyo Research Laboratory, Sanyo Kokusaku Pulp Co., Ltd.
}

In general, beating can be classified to two groups which are called "wet beating" and "free beating". This report deals with the effect of beating conditions on shrinkage of the sheets during drying. Hardwood and softwood bleached sulfate pulps were beaten with a Niagara beater under various conditions of temperature, pulp consistency and load during beating Handsheets made from beaten furnishes were compared with each other in regard to sheet shrinkage during drying and dimensional stability of the sheet. These results obtained are summerized as follows :

1) When handsheets were prepared from unbeaten or slightly beaten pulps, shrinkage of the sheets from hardwood pulp was smaller than that from softwood pulp. As beating was greatly exceeded, shrinkage of the sheets from hardwood pulp increased more evidently than that from softwood pulp.

2) As compared with the sheets made from wet beaten pulps, the sheets from freely beaten pulps shrank more greatly during drying, but showed less stress during its shrinking.

3) Shrinkage during drying was affected greatly by length of the fiber which composed the sheets. That is, sheets composed of comparablly long fibers showed larger shrinking stress but less shrinkage during drying.

4) Pulps beaten freely were shorter in length of fiber than wet beaten pulps of comparable C.S. F. so the sheets made from freely beaten pulps were more unstable in dimensional stabilitythan those from wet beaten pulps. With regard to light scattering coefficient and another physical properties, the difference between the sheets dried with restriction to shrink and those without it was more evident in freely beaten pulp.

\section{1. 緒言}

原料パルプの叨解を進めるにしたがって，シート乾 燥時の収縮が大きくなり，紙の伸縮安定性が低下する ことは周知のと㧍りである ${ }^{1)-6)}$ 。伸縮安定性は乾燥時
の収縮量によってきまることはすでに述べた ${ }^{78)}$ が， この乾燥時の収縮に及ぼす吒解の影響については, “Conformability”が高くなるからであるといら説明 がなされている程度であり, その因子については未だ 解明されているとはいえず，收縮を起こしにくく，且

この研究を「紙の伸縮安定性に関する研究」第 3 報とする。 
つ，強度のトがり罗い織維形態をもたらす叮解方式に ついての究明はない。

そこでLBKP 及びNBKP について，同一ビーター を用い, 叨解時のパルプ濃度, 叮解温度及び叨解荷重 を変え, 貿なった条件下で種々のろ水度にまでパルプ を吒解し，シート乾燥侍の収縮挙動及び得られた紙の 物性について誠べ，よりよい吒解状態についての考察 を行った。

\section{2. 実験方法}

\section{1 吅解}

材販 LBKP (国産), NBKP (北米産)を, $20 l$ ナ イヤガラビーターを用い，下記のように条件を変えて 叮解を行った。

$\begin{array}{lccc} & \text { パルプ濃度 } & \text { 吒解温度 } & \text { 荷重 } \\ \text { 川解条件 } 1 & 2.0 \% & 10^{\circ} \mathrm{C} & \text { 標準 } \\ \text { 川解条件 } 2 & 0.5 \% & 45^{\circ} \mathrm{C} & \text { 標準 } \times 2\end{array}$

夘解武料は正規の方法でろ水度を測定し，また，プ レパラートを作成して, 平均繊維長を測定した。手す き紙の乾燥は回転试ドライヤーを用いた。

\section{2 収縮応力及び収縮率の測定}

手すきウェットシートから，幅 $6 \mathrm{~cm}$, 長さ $10 \mathrm{~cm}$ の 試料を切り取り，颌報多で述べた方法によって收縮応 力の测定を行った。收維応力は断面積当りの值に換算 して表示した。收縮応力測定後の試料については光散 乱係数も测定した。また, 乾燥時のシート収縮率は, 一定スパンの乾燥前後の長さ変化をノギスで測定した。

\section{3. 実験結果並びに考察}

\section{1 吒解による繊維長の変化}

LBKP 及び NBKP について吒解条件を変えたとき の繊維の状態の相違を調べた。吒解機の形式によって, 織維が受ける機械的な力はかなり異なり9，粘状吒解 が起こり易い吒解方式, 遊離状吒解が起こり易い吒解 方式とがあるが，ここではナイヤガラビーターを用い， 吒解条件を大幅に変えて, 意識的に粘状, 遊離状の差 をつけた。

粘状吒解, 逰離状吒解という概念は, 処理されたパ ルプの形態の結果に対して与えられるものであり，し たがって，パルプの種類すなわち繊維形態が異なると， 问一夘解条件でも粘状, 遊離状の傾向が逆になること があるが，表 1 に示した通り，LBKP，NBKP とも に明らかに吒解条件によって吒解状態がかなり異なり， しかも同一の傾向を示していることが分かる。高温, 低濃度, 高荷重叨解を行ったパルプは, 同一ろ水度の 通常吒解条件のパルプよりも保水度が低く, 繊維長は
短かく、、わゆる遊晟状吒解を受けていると考えられ る。万水度約 $250 \mathrm{~m} l$ (C.S.F.) の パルプの瀻維長分 布を図 1 に示したが，この結果も吒解条件の相違を示 している。

\section{2 吒解による収縮性の变化}

上記のパルプについてシート乾燥時の収縮応力を測 定し, 図 2 亿示した。LBKP は全ろ水度域にわたり, 吒解によってほぼ直線的に收縮応力が増大するが， NBKP の場合は, 吒解初期に急激に収縮応力が増加 し，その後はゅるやかな増加にとどまる。従って高ろ 水度域では NBKP の方が LBKP よりも収縮応力が 大きいが，叮解の進行にともなって両者の差は小さく なり, 殊にろ水度 $200 \mathrm{~m} l$ 以下にまで吅解したパルプ では LBKP, NBKP の収縮応力の差は認められなか った。吒解初期においては瀻維の形態の影響が大きい ために，柔軟で瀻維間接触が大きく，しかも，繊維が 長いために繊維間のずれ抵抗が大きい NBKP シート の方が高い収縮応力を示す。しかし，叨解が進行する と, LBKP の場合も纎維間接触が急速に增大し, NBKP と同程度の収縮応力を示すようになるといえ る。 $\mathrm{SP}$ ほど極端ではないが，KP の場合でも $\mathrm{N}$ パル プでは叮解初期に内部フィブリル化によって紙の強度, 殊に引張強さなどが急激に向上することはよく知られ ている ${ }^{10) 11}$ が，収縮応力も同様の傾向を示すと考えて よい。

また， L・NBKP とも粘状，遊離状吒解による收縮 応力の変化はあまり相違ないが, 遊離状吒解時の方が 若干小さい值を示した。これは, 遊離状吒解パルプは 内部, 外部フィブリル化が少なく，しかも繊維長が短 かいため, 繊維間の絡み合いが少ないことによるもの と考えられる。

次いで収縮率についてみると, 表1からも分かるよ うに LBKP は未叨解時には NBKP よりもむしろ小 さいが, 叨解の進行にともなって次第に収縮率が増 大する。叨解による収縮率の增大は NBKP 上りも LBKP の方が大きいことが分かった。また，遊晟状 叨解パルプは粘状吒解パルプよりも全叮解域にわたっ て収縮率が若干大きかった。収縮率と収縮応力の関係 を図 3 に示したが，LBKP はNBKP に比へ，また， 遊離状吒解パルプは粘状吒解パルプに比べ，同一収縮 率での収縮応力は小さい。それぞれの吒解において, 収縮率一収縮応力はほぼ直線関係にあるが，パルプの 種類, 吒解の状態によってこの関係は相違しておうり, 収縮率の小さいものほど収縮応力が大きい傾向が認め られる。収縮応力は乾燥時の繊維収縮による瀻維間の ずれの抵抗を測定しているものであって，絡み合いそ 


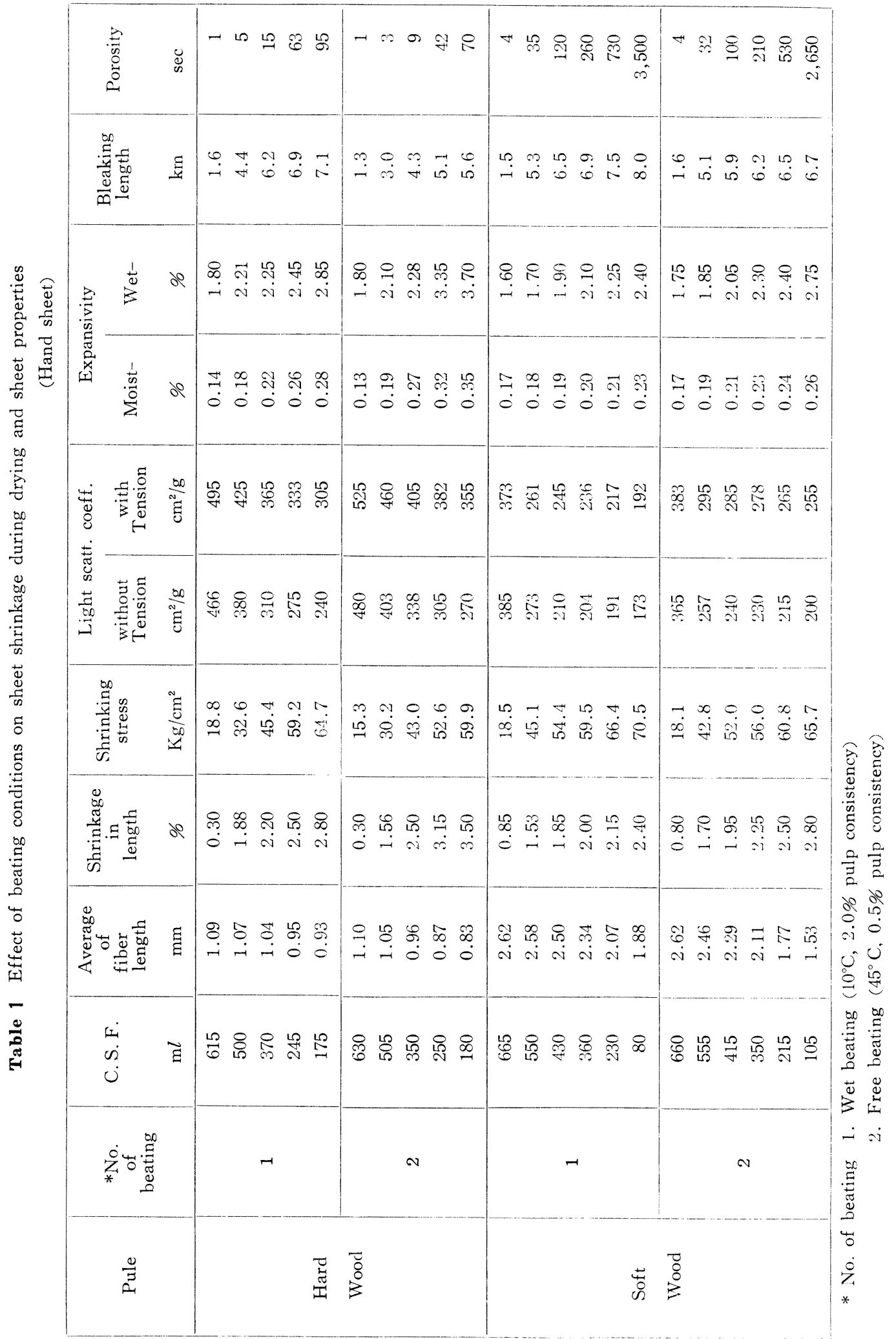



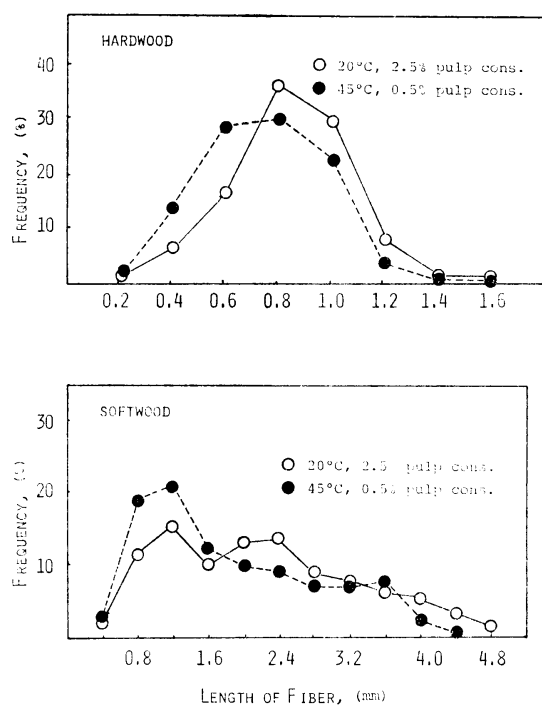

Fig. 1 Frequency curves of fiber length of furnishes beaten to about $250 \mathrm{ml}$ C. S. F. by Niagara beater

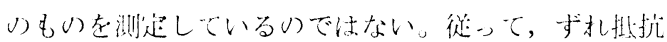
り大きいものほど收維率が小さいこととなり，シート を構成している䋐維が钱いほど，峦い変えれば，一本 の繊維が数多くの䋐維閂にわたって絡み合っているシ ートほど収絥忍力は大きいが，収維率は小さくなると いえよう。このように仪䋧に関しては繊維長の影響は 柤めて大きいことが分かる。

\section{3 繊維長と収縮性の関係}

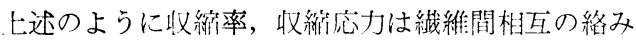
合いによって左有され，したがって，繊維壁厚などの

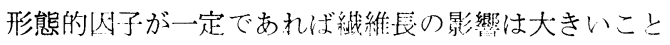

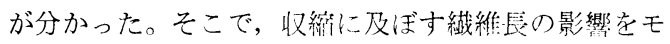
デル的に淍べるために次の笑験茕行った。

ろ水度 $350 \mathrm{~m} l の N B K P$ を長網テスト抄紙機で抄紙 し，乾燥したこのシートを流れ方向に種々の長さに断

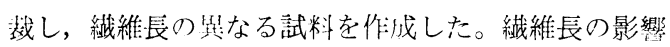
つみを調べるためには, 叮解条件が同一でなければ比 較試料とならず, したがって吒解封間の相違, 叮解後 のふるい分けなどで繊維長の異なるフラクションを作 っても意味がない。そこで，上䛉のように，间一吒解 武料から断裁によってランダムに繊維を切断し，断裁 長さを変えることによって半均繊維長の異なる試料を

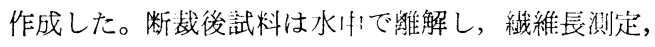

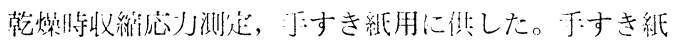

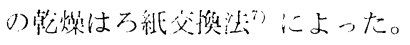

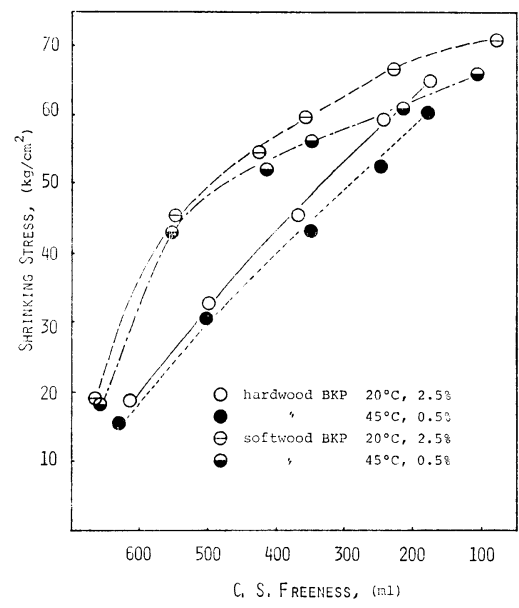

Fig. 2 Effect of beating condition on shrinking stress during drying of handsheets

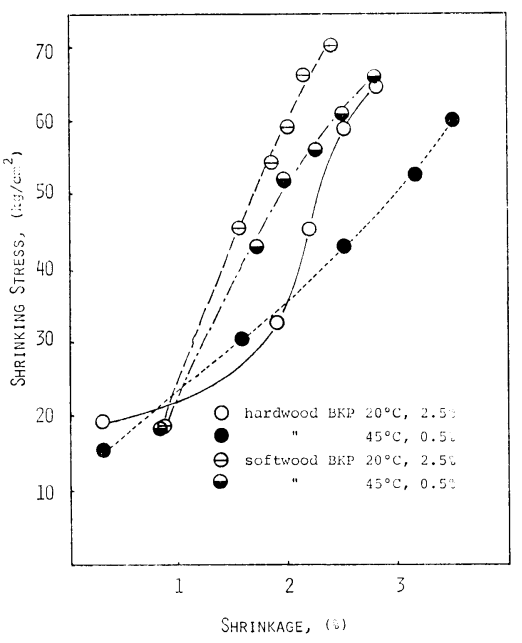

Fig. 3 Relation between shrinkage and shrinking stress during drying of handsheets from furnishes beaten in different conditions

結果を表 2 に示した。断䇅さず, 将離解のみのパル プから作成したシートは，原パルプのシートに比べ， 一次抄紙（長網テスト抄紙機すき）の際に微紐繊維が 減少しているため ${ }^{6)}$ ，中均繊維長が想干增大しており， また乾燥の影響もあって，子水度が者嘎加し，仪維

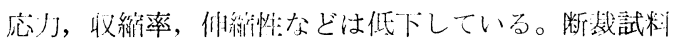

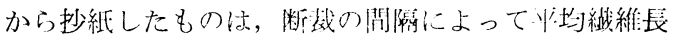


Teble 2 Properties of handsheets made from furnishes of cut sheets (Hardwood Pulp)

\begin{tabular}{|c|c|c|c|c|c|c|}
\hline $\begin{array}{c}\text { Cutting } \\
\text { length } \\
(\mathrm{mm})\end{array}$ & C.S.F. & $\begin{array}{c}\text { Average } \\
\text { of } \\
\text { fiber } \\
\text { length } \\
(\mathrm{mm})\end{array}$ & $\begin{array}{c}\text { Shrinkage } \\
\text { in } \\
\text { length }\end{array}$ & $\begin{array}{c}\text { Shrinking } \\
\text { stress }\end{array}$ & $\begin{array}{c}\text { Light scatt. } \\
\text { coeff. }\end{array}$ & $\begin{array}{c}\text { Moist- } \\
\text { expansivity }\end{array}$ \\
\hline $\begin{array}{l}\text { Original } \\
\text { furnish }\end{array}$ & 355 & 2.38 & 2.05 & 58.8 & 200 & 0.21 \\
uncut & 375 & 2.44 & 1.95 & 57.6 & 215 & 0.19 \\
5.0 & 350 & 2.03 & 2.05 & 52.4 & 210 & 0.22 \\
3.5 & 330 & 1.74 & 2.30 & 46.8 & 200 & 0.24 \\
\hline
\end{tabular}

が徐々に変化しており, 繊維長の短かいものほど収縮 応力は小さいが, 収縮率, 伸縮性は増加の傾向を示し ていることが分かる。このことから, 収縮に及ぼす緎 維長の影響は極めて大きいことが明確になったと考え てよいであろう。

\section{4 シートの特性}

湿紙匹乾燥時の収縮挙動については以上の通りであ るが，さらに乾燥紙の特性について調べた。

まず, 繊維間結合の指唀としてシートの光散乱係数 の変化を図 4 に示した。N材パルプとL材パルプの相 違は周知の通りである。NBKP はろ水度全域におい て LBKP よりも光散乱が少ないが，殊に，叨解初期 において急激に低下し, それ以後, 低下率が非常にゆ るやかになるのに反し，LBKP は吒解により，ほぼ 直線的に光散乱が低下する。ろ水度一収縮応力の関係 と類似の傾向を示すといえよう。叨解条件の違いによ る光散乱の差はそれほど大きくはないが，粘状叨解パ ルプの方が光散乱がやや少なく，繊維間結合が多いこ とを示しており，収縮応力の䝨向と一致する。

次に吒解による伸縮性の変化を図 5 に示した。 LBKP, NBKP の差, 粘状叮解, 遊㒕状吒解の差が 非常に明瞭に現われている。すなわち，粘状吒解によ る LBKP, NBKP の比較を行うと, 叮解初期には はむしろ LBKP よりも伸縮安定性は高いが，叮解に よって直線的に，しかも急速に低下していくのに反し， NBKP は叮解による伸縮安定性の変化が少ない。ま た，遊離状叨解パルプは NBKP， LBKP ともに粘状

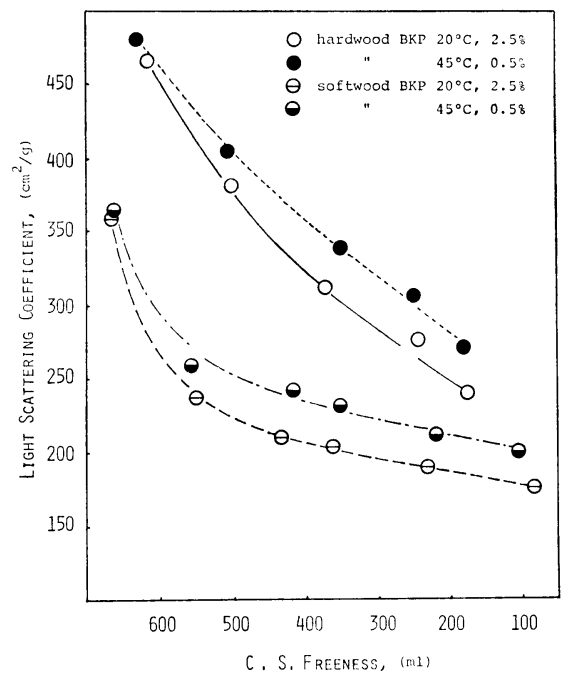

Fig. 4 Effect of beating condition on light scattering coefficient of handsheets

川解パルプよりも伸縮安定性の変化が大きいことが分 かる。

このように，パルプの種類，川解の状態によってそ れから得られたシートの伸紑安定性が異なるが，図 6 に示したように，収縮率と伸縮率の関係をみると，原 料による相違は悡められなくなる。従って，これまで にも述べたように，伸縮安定性は乾燥時の収緢率によ 


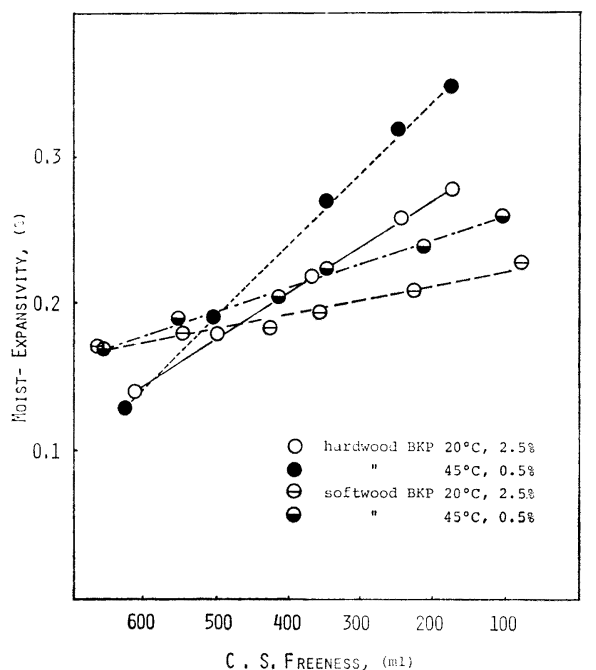

Fig. 5 Effect of beating conditon on moist expansivity of handsheets

って決定されるといえる。このことから，伸縮安定性 の高い紙を作るためには，乾燥時に收縮を起こし難い 原料を用いることが望ましい。図 7 亿，回転式ドライ ヤーで乾燥した収縮乾燥シートと, 収縮応力を測定し たシート, すなわち, 乾燥時に収縮を抑制したシート の比散乱係数の比較を示した。比散乱係数の差は, 收 縮抑制乾燥したために，本来繊維間結合，ある心は， 纎維間接触によって光を散乱しなくなる距離にまで近 うく繊維同志が，その密着を妨げられたために起こ。 たものであり，収縮率の大きいパルプほどこの差が大 きいことを明瞭に示している。

\section{4. 結 論}

LBKP 及びNBKP を用い，シート乾燥時の収縮性 に及ぼす吒解条件の影響を調べ，次の結果を得た。

1） LBKP は粗叮解持には NBKP 上りも収縮性が 小さいが，叮解の進行に伴ない LBKP の収縮性は急 激比增大する。

2）遊離状吒解パルプは粘状吒解パルプに比ベ，收 縮応力が小さいが，収縮率はむしろ大きい。

3）繊維長は，乾燥時のシート収縮性に大きく影響 する。長い繊維から構成されるシートは収縮応力は大 きいが収縮率は小さい。

4）乾燥時に収縮を抑制すると，シートの比散乱係 数は大きくなるが，収縮率，伸縮不安定性の大きいパ ルプ程, 収縮乾燥, 無収縮乾燥両シートの.比散乱係数 の差が大きい。

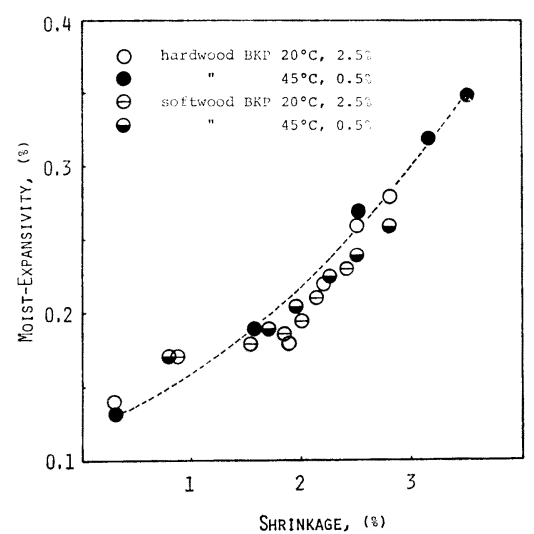

Fig. 6 Moist-expansivity as a function of shrinkage during drying of handsheets from furnishes beaten in different condition

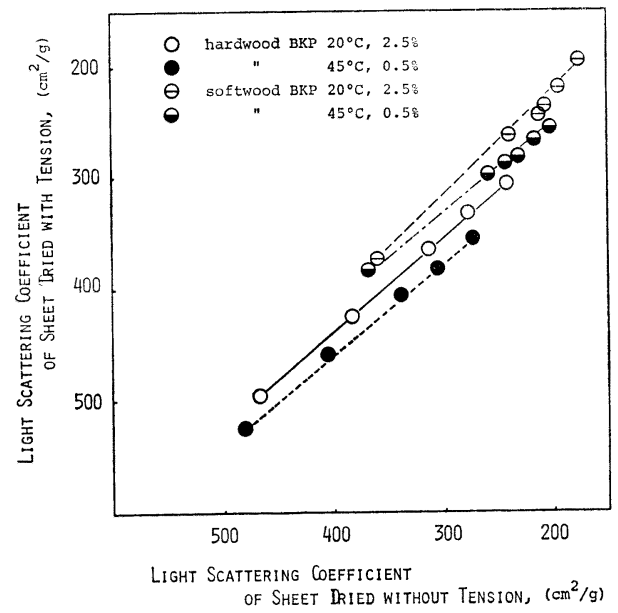

Fig. 7 Relations of light scattering coefficient of handsheets dried with and without tension

5） LBKP，NBKP ともに, 遊離状叨解パルプは, 粘状吒解パルプに比べて瀻維長が短かいため伸縮安 定性が低く，したがって収縮抑制による紙質の変化も 大きい。

\section{文献}

1) Raderer, P.: Wochenbl. Papierfabrik. 95, (1), 9, (1967)

2) Newman, J. A. S. : Das Papier 17, (10), 491, (1963)

3) Forgacs, O. L., Robertson, A. A. and Mason, S. V. : "Fundamentals of Papermaking Fibre" 